\title{
Robosub: A Contest-based Multidisciplinary Senior Design Capstone Project
}

\section{Dr. Todd Kaiser, Montana State University}

Dr. Todd J. Kaiser is an Associate Professor in the electrical and computer engineering department at Montana State University (MSU). Dr. Kaiser teaches and conducts research in the area of microfabrication of sensors and actuators. He has developed four microfabrication based courses where students use a clean room facility to fabricate transistors, solar cells or MEMS structures. Dr. Kaiser's research group is currently creating radiation sensors for a radiation tolerant computer system for space flights on satellites and in the International Space Station. 


\title{
Robosub: A Contest-Based Multidisciplinary Senior Design Capstone Project
}

\begin{abstract}
A team of senior engineering students from Montana State University has competed for the past 5 years in the Association for Unmanned Vehicle Systems International (AUVSI) Robosub competition, held annually in late July in San Diego, CA. The competition requires an autonomous submarine to traverse through various regions within a pool and complete designated missions which require navigation, actuation and control. The interdisciplinary capstone teams have been assembled from three different departments represented by students majoring in Mechanical Engineering, Mechanical Engineering Technology, Electrical Engineering, Computer Engineering and Computer Science. This paper will present an overview of the multidisciplinary capstone project, the lessons-learned from running several iterations of the project and recommendations for further improvements. It will present ideas and methods that should assist faculty at other small institutions in implementing similar contest-based multidisciplinary capstone project.
\end{abstract}

\section{Introduction}

The value of competition based senior design projects has been reported across numerous disciplines. Electrical engineering students have created micromouse and line-maze solving robots $^{1}$, while electrical and mechanical engineering students have developed autonomous ground vehicles ${ }^{2}$, and civil engineering students have gone through the design/build process to create concrete canoes for competitions. ${ }^{3}$ Many of these competitions have corporate and governmental agency sponsors. NASA has sponsored an annual Lunabotics Mining Competition since 2010, where student engineering teams design and build a remote-controlled excavator for harvesting lunar soil. ${ }^{4,5}$ The Shell Eco-Marathon challenges students to design, build and drive a self-built energy efficient car. ${ }^{6}$ The Air Force Research Laboratory University Nanosatellite Program competition tasks teams to design and deliver a small satellite that will accomplish a real-world mission. ${ }^{7}$ Others have reported on their continuous design/build competition projects such as the ASME Human Powered Vehicle and SAE Formula Series. ${ }^{8}$ Paulk and Krishan presented their results and evolution of their capstone over a 15 year period. ${ }^{9}$ They all report that the benefits, such as the competition creates student excitement and motivation and the format mimics industry product designs with deadlines, outweigh the challenges. The main challenges mentioned are the substantial faculty engagement required and the teams often fall into the ends justify the means design without following proper design methodology. 


\section{Competition Rules and Missions}

The AUVSI Foundation initiated the Robosub competition to provide opportunities for undergraduate students to experience the challenges of system engineering and to expose students to working on interdisciplinary teams while engaging industrial partners. In parallel the students develop the skill set necessary to accomplish realistic missions with autonomous vehicles. The missions vary slightly from year to year. They are not designed to be grand challenges that push the state-of-the-art technology, but rather give an opportunity that allows students an appreciation for the trade-offs required in any system design, and a chance to apply lessons learned from transitioning a design and prototype to an operating working model. ${ }^{10}$

The venue is the SSC Pacific TRANSDEC anechoic pool as seen in Figure 1. It is a 300' x 200' $\mathrm{x} 38^{\prime}$ ' deep chemically treated freshwater man-made pool that contains 6 million gallons of water which is continuously circulated to maintain isotherm conditions. The elliptical pool is divided in half along its minor axis creating two sides for the layout of the mission tasks. One side is used as a practice area and the other is used for the competition. As stated earlier the missions vary from year to year, the 2015 theme for the completion was based on the 'Back to the Future' movie trilogy, and it will be highlighted in this paper as an example of the types of tasks and missions the vehicles are asked to complete.

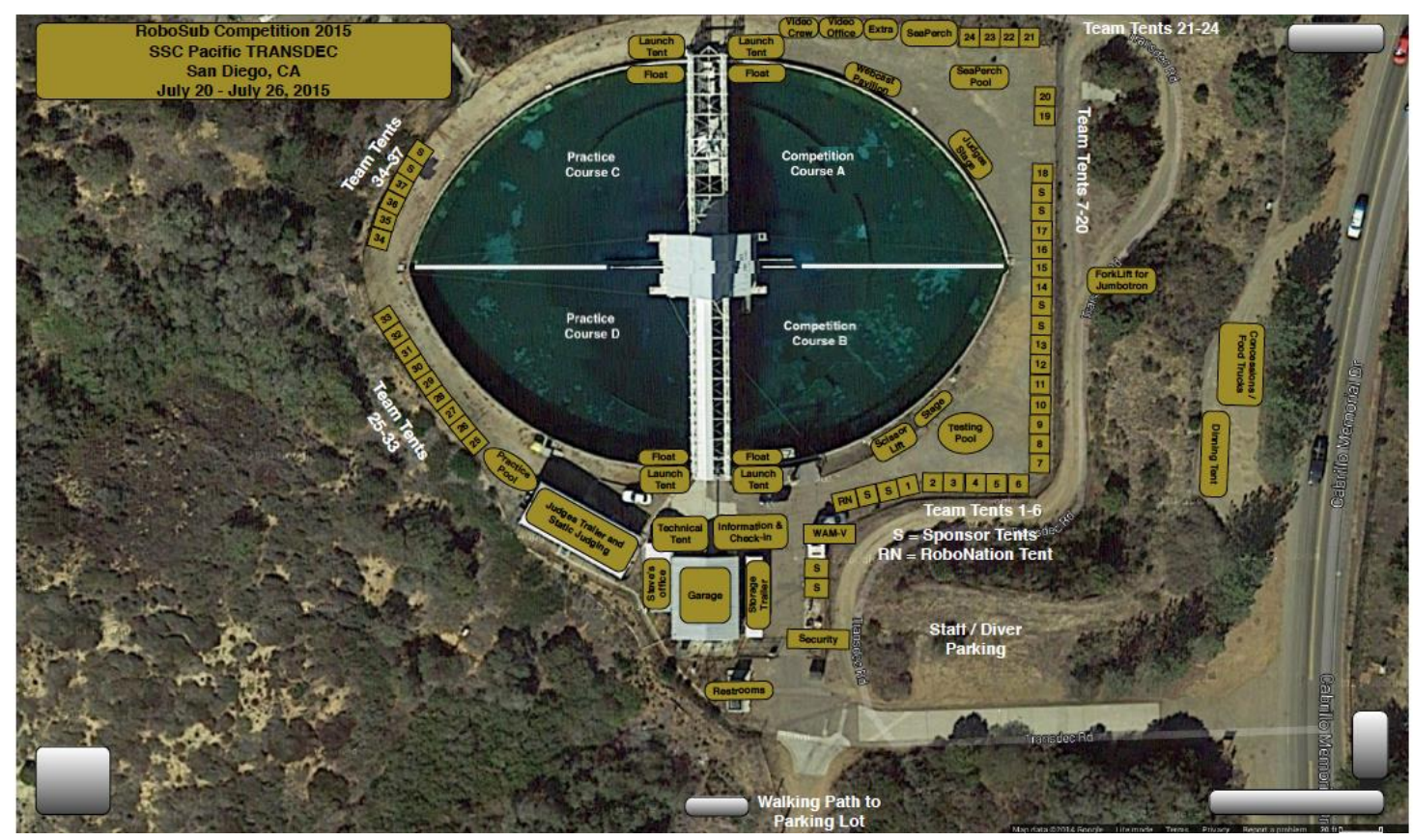

Figure 1. Site Map of the 200' x 300' anechoic pool used for the completion. ${ }^{10}$ 


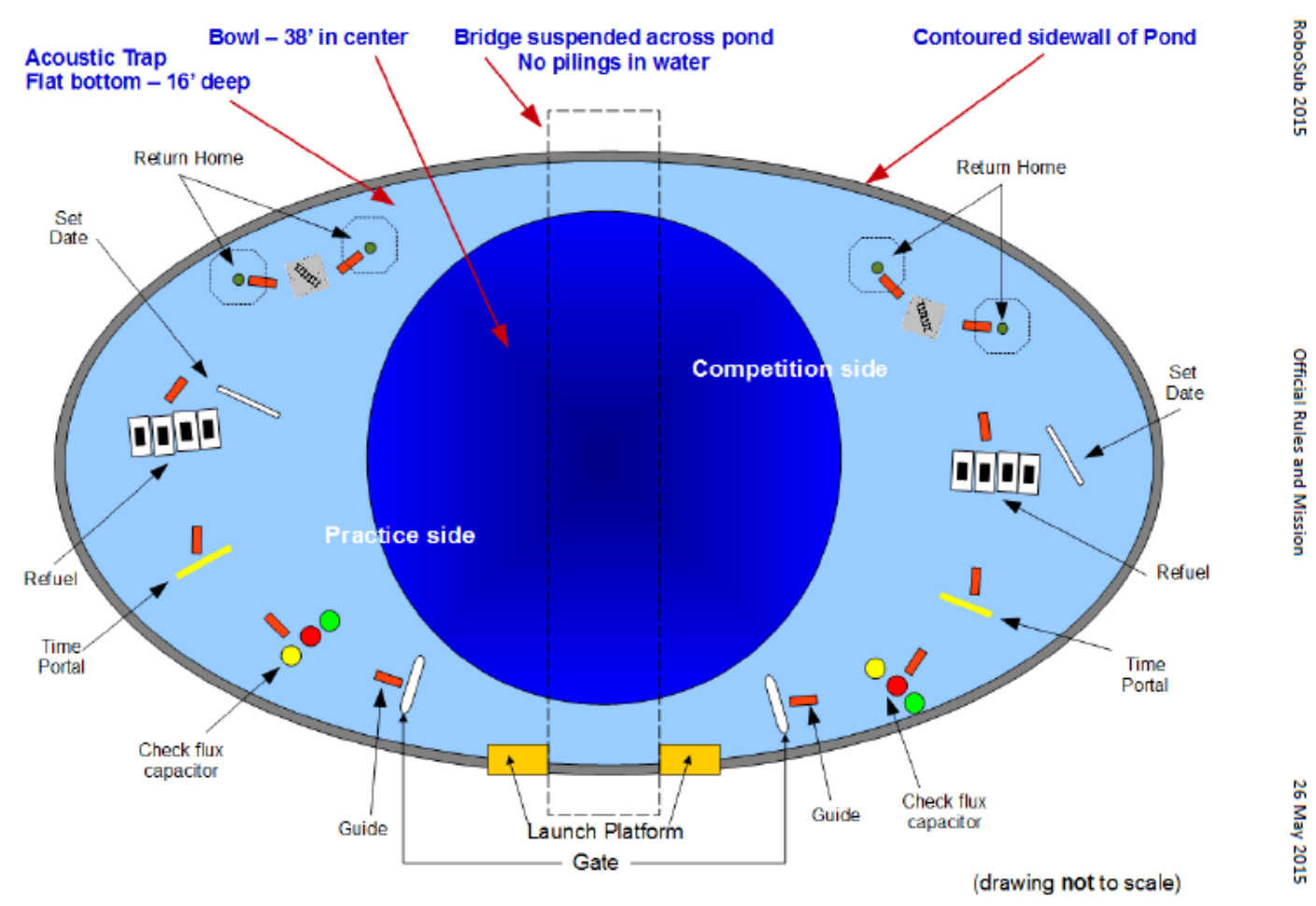

Figure 2. General Layout of the Arena. The arena is split into a practice side (left) and a competition side (right). ${ }^{11}$

An autonomous underwater vehicle (AUV) demonstrates its autonomy by completing a series of underwater 'Back to the Future' missions. The first task, which the autonomous vehicle must complete before it moves on to any other task, is to pass through an underwater gate. The gate is slightly below the surface and covered with blaze orange duct tape. This preliminary test is to ensure that all vehicles can maintain depth and move in a straight path. Maximum credit is given for moving straight through the gate, while partial credit is awarded for curves, swerves and other perturbations.

Each subsequent task is directionally linked by a path marker or guide that is anchored 1-2 feet from the bottom of the pool; see Figure 2. The guide is 4 feet long and 6 inches wide also covered with blaze orange duct tape. They are situated such that following the segment lengthwise will lead to the next task.

Check the 'Flux Capacitor' is the first 'Back to the Future' mission. This exercise consists of tapping three different colored underwater anchored buoys in the proper order. The buoys are shades of red, yellow and green.

The 'Time Portal' task requires the underwater autonomous vehicle to pass over a horizontal section of an eight foot long plastic pipe suspended under water. More points are awarded for 
passing through the portal with 'style', that is either passing over the midpoint sliding sideways or backwards.

The 'Refuel Task' forces the robosub to remove an orange colored lid with a purple handle from a black bin, then drop markers into the bins. There are four bins, one of which is the primary and is also covered. The remaining uncovered bins are secondary targets. The sub can carry up to two droppers. The most points are awarded for dropping the first marker into the primary target then dropping the backup marker into secondary target. Partial credit is awarded for dropping a marker into any target.

The 'Set Date Task' consists of firing torpedoes through openings with numbers corresponding to the critical dates of the movies broken down into two digits. The holes are labeled 18, $19 \& 20$ for the century and 85, 55 and 15 to make the possible years in the movies: $1885,1955,1985 \&$ 2015. Points are awarded for firing one of two torpedoes through any hole, but more credit is given for firing the two torpedoes in the proper order and in the proper holes to create one of the corresponding years. One of the holes is covered with an orange door and purple handle which must be slid open to receive the maximum credit for firing through.

The 'Recovery Area' is the final task area. Here the sub is asked to pick up and place objects. Continuing with the 'Back to the Future' theme, the targets are labeled train and DeLorean and must be placed on a set of railroad tracks positioned on the bottom of the pool. Once the sub has completed its missions it is to surface, but in order to obtain full credit the vehicle should surface within an octagon region that is marked by an acoustic pinger located 2 feet off the bottom of the pool centered under the octagon.

There are additional constraints on the size and weight of the submarine and specifications for the markers and torpedoes. Table 1 lists the scoring metrics for the mission performance tests. 
Table 1. Performance Measure Point Breakdown. ${ }^{12}$

\begin{tabular}{|c|c|}
\hline Performance Measures & Maximum Points \\
\hline Weight & $\begin{array}{l}\text { Overweight penalty }-5 / \mathrm{lb} \text {. over } 84 \mathrm{lbs} \text {. } \\
\text { Underweight bonus } 80+\mathrm{lbs} \text {. under } 48.5 \mathrm{lbs} \text {. }\end{array}$ \\
\hline Marker/Torpedo specifications & -500 per marker not meeting specifications \\
\hline Pass through validation gate & 100 \\
\hline Maintain a fixed heading through gate & 150 \\
\hline Follow the "path" & 100/segment \\
\hline Check Flux Capacitor (any color, Red then Green) & 400,800 \\
\hline $\begin{array}{l}\text { Time Portal }(>1 / 2,<1 / 2) \\
\text { Straight through // with style }\end{array}$ & $\begin{array}{l}400,600 \\
1000 / / 1400\end{array}$ \\
\hline Refuel: remove lid & 700 \\
\hline Refuel: any, primary/secondary & $500,1200 /$ marker \\
\hline Set Date: remove lid & 700 \\
\hline Set Date: any: large: small & $500,1000,1500 /$ torpedo \\
\hline Surface within Octagon & 500 \\
\hline Surface with Object & 600/object \\
\hline Drop the Object & 200/object \\
\hline Object on Railroad & 1000/object \\
\hline DeLorean in front of train on tracks & 1000 \\
\hline Finish the mission with $\mathbf{T}$ minutes left & $\mathrm{T} \times 100$ \\
\hline
\end{tabular}

\section{Capstone Sequence}

The engineering design sequence is covered in the last three semesters of the students' engineering program. The sequence starts with a course in multidisciplinary design taken at the end of the junior year. This three credit course (EGEN310) introduces engineering students across multiple engineering disciplines to the creative design process, project management and technical leadership, while highlighting the skills needed to work in a multi-disciplinary environment. See Table 2. 
Table 2. Capstone Sequences

\begin{tabular}{|c|c|c|c|}
\hline $\begin{array}{l}\text { Computer Science } \\
\text { Interdisciplinary Option }\end{array}$ & $\begin{array}{l}\text { Mechanical } \\
\text { Engineering }\end{array}$ & $\begin{array}{l}\text { Electrical and Computer } \\
\text { Engineering }\end{array}$ & $\begin{array}{l}\text { Mechanical Engineering } \\
\text { Technology }\end{array}$ \\
\hline EGEN310 (3) & EGEN310 (3) & EGEN310 (3) & EGEN310 (3) \\
\hline CSCI482R (1) & EMEC489R (2) & EELE488R (2) & ETME489R (2) \\
\hline CSCI483R (3) & EMEC499R (3) & EELE489R (3) & ETME499R (3) \\
\hline
\end{tabular}

The capstone project immediately follows (CSCI482 \& 483, EMEC489 \& 499, EELE488 \& 489, or ETME489 \& 499). The departments each have their own capstone rubrics. This is a two course sequence that can be roughly broken down into design with critical subsystem demonstration and then fabrication with characterization. Each semester has check point design reviews or product readiness reviews.
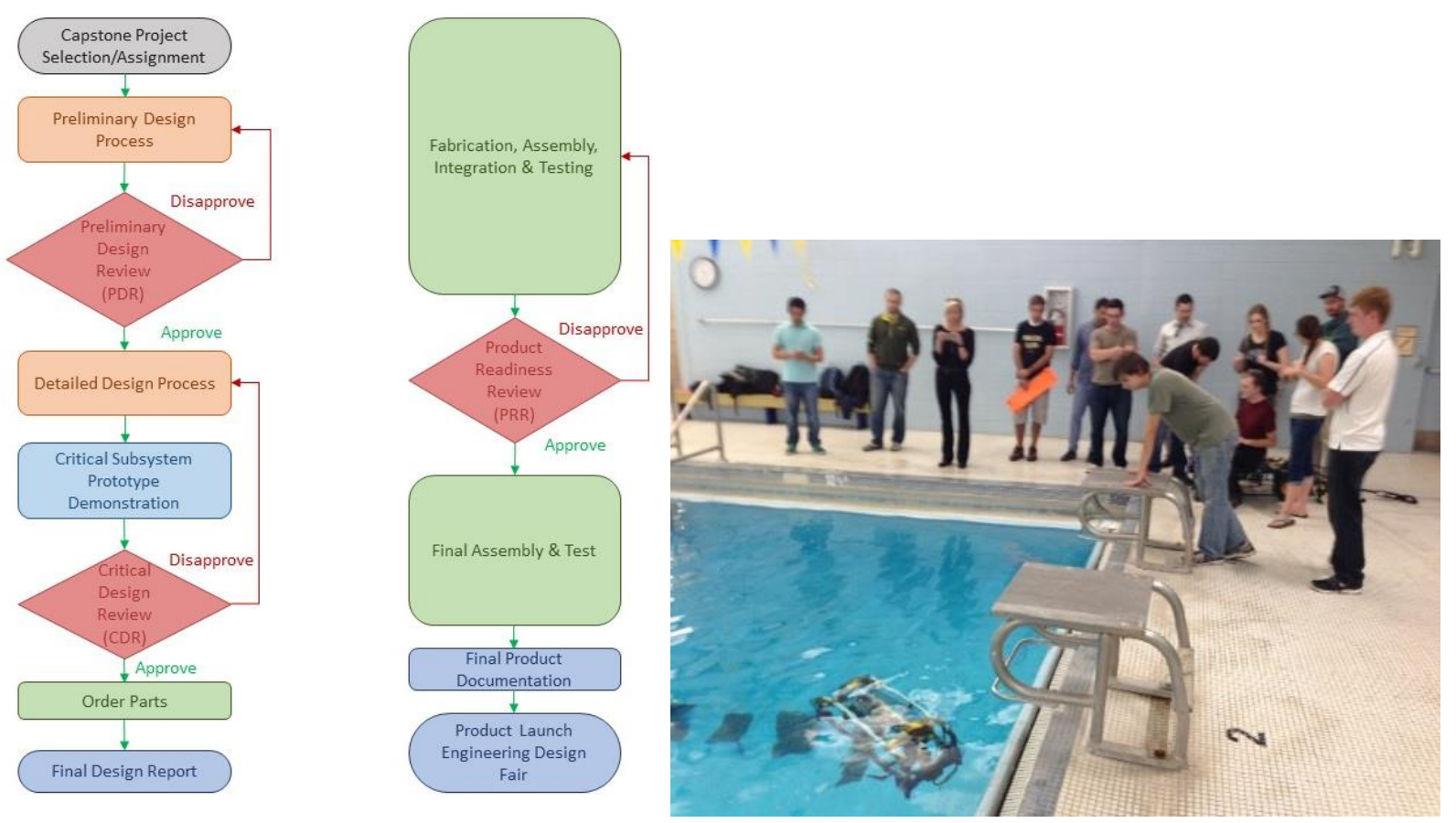

Figure 3.Two Semester Senior Capstone Design Flow with Image of a Product Readiness Review (PPR) Session.

The reviews are presentations to their peers that includes students in both capstone sequence courses. Students are requested to assess the team's progress and recommend whether the project should continue to the next step or return to the previous step and address issues unveiled by the review. See Figure 3. 

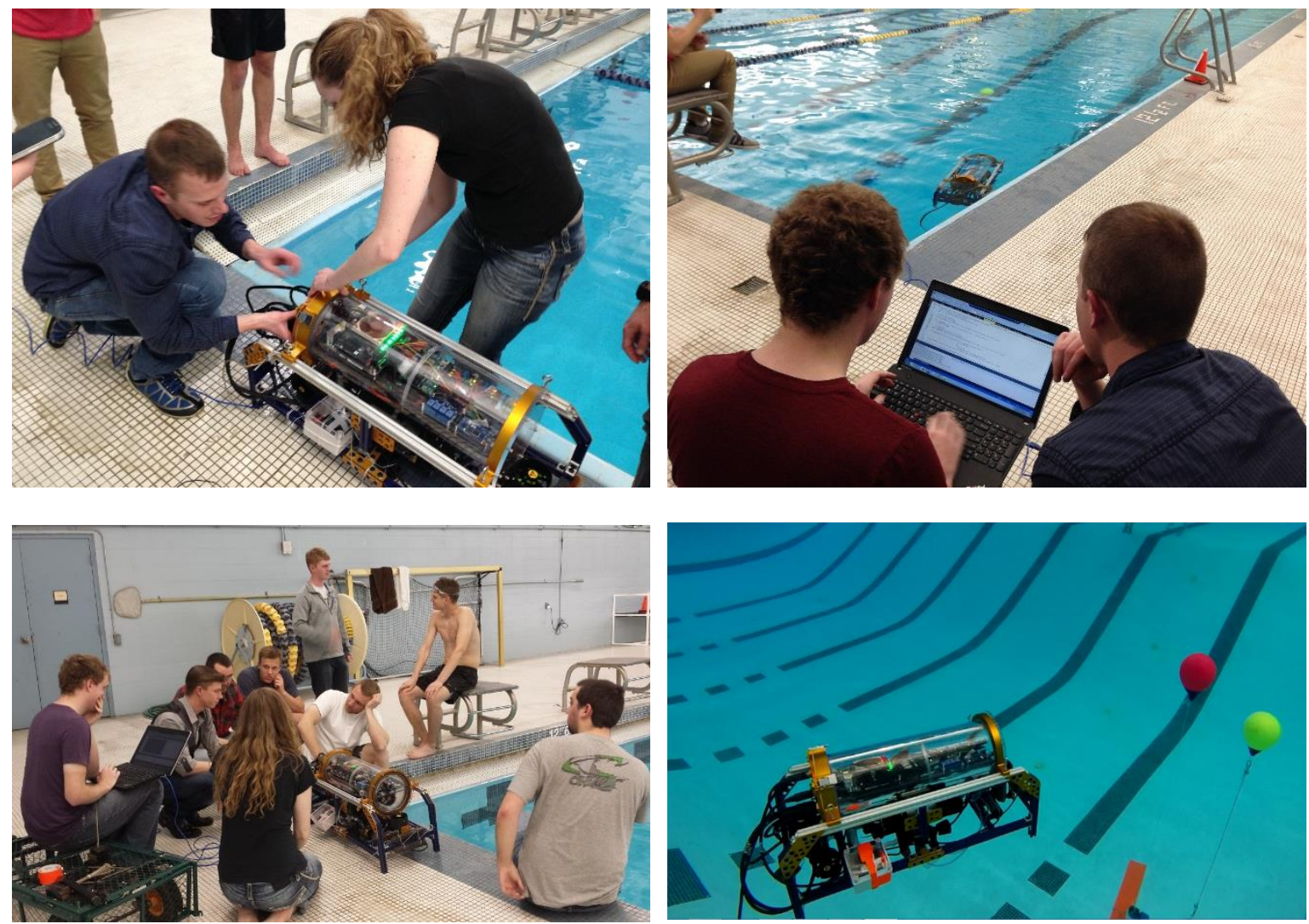

Figure 4. Weekly Robosub Testing Sessions

\section{Time Line}

The first three years of these capstone projects were ran through the mechanical engineering (ME) department, and all students were required to meet the course requirements of the ME department. In each of these years the students started from scratch and developed a new submarine without major input from faculty or previous design teams. See Figure 5. The first year (F'10-S'11) used a water tight Pelican case to house the electronics with a minimal external frame. The following year (F'11-S'12) moved to a Plexiglas tube with endcaps and a large external frame. The third of these designs was a compromise of the previous systems, still using the Plexiglas tube to house and protect the electronics, but with a smaller external frame to mount the motors and extra paraphernalia which included a separate camera housing. Each of these teams performed marginally well, all were able to maintain depth and proceed through the test gate, but none were able to perform any of the subsequent tasks. 

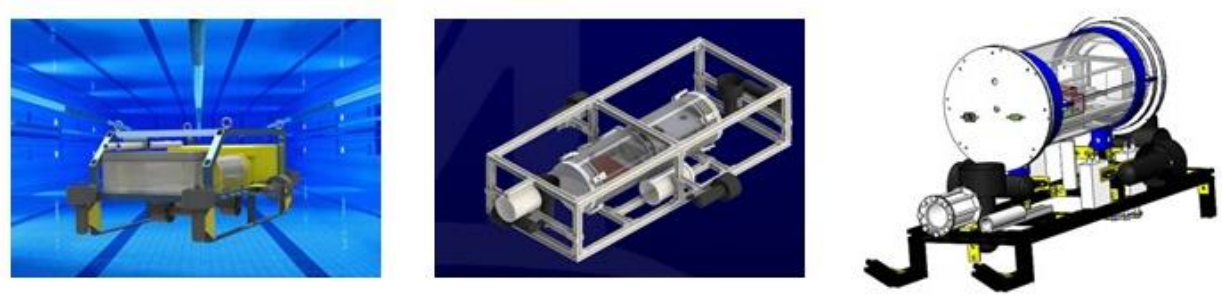

Figure 5. First Three Robosub Designs

The next series of Robosub design projects were housed in the Electrical and Computer Engineering department (ECE). This was mainly done due to the significant increase in the enrollment in the ME department. To reduce the ME faculty capstone advising load, this and several other multidisciplinary projects were moved to the ECE department. The senior capstone teams were required to meet the deliverables of the faculty advisor's home department, which was now the ECE department. The first year under the ECE department, a second auxiliary team was created. Their task was to improve on the navigation issues of previous teams by adding an inertial measurement unit (IMU) to robosub system. They were also tasked with generating the software for calibrating and integrating the sensors with the autonomous navigation scheme.

It became apparent if the teams were to progress further in the competition, a new methodology was going to have to be implemented. First, rather than have the teams start from ground zero each year, they were asked to assess the previous year's work and use the previous year's designs for the parts or tasks that they deemed successful. Additional capabilities or improvements to the design were encouraged, but at a smaller scale. It was explained to the students as in the automotive industry, new models are not generated every year, but rather, each year new features are added or improvements are made. The F'14-S'15 team focused on making the endcaps of the capsule water tight with wet-connects that were reusable and easily adapted for adding further connections and capabilities. They also developed the computer vision and color recognition software. With this added capability the team was able to move through the gate, track the bottom guides and tap the colored buoys. 


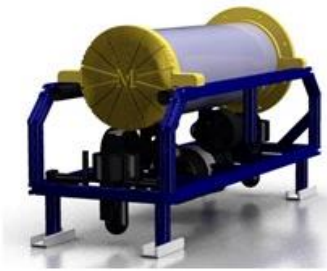

Navigation \& IMU Integration

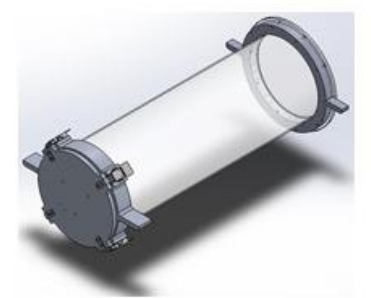

Computer Vision Control

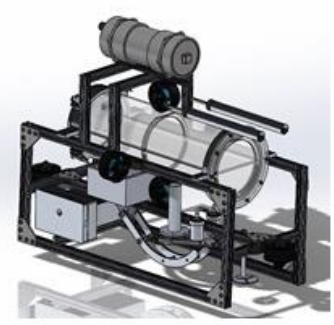

Hydrophone

Pinger Locator
Mechanical Arm
Torpedo Launch \& Dropper
Computer

Targeting

\section{Robosub Club}

Figure 6. Current timeline of the Robosub Capstones with overlapping teams working on adding capability and functionality to the autonomous vehicle. Major modifications to the design are highlighted blue for electrical engineering, orange for software upgrades and green for mechanical system upgrades.

The second modification to the capstone project was to create an additional team that would start out of semester sequence with the previous team. This Spring-Fall team, rather than a Fall-Spring team was tasked with the mechanical system for dropping markers and launching torpedoes. Part of the system requirements for their design was to seamlessly integrate the current robosub systems into their project. This modification also created some continuity in the student's working knowledge on the project. In past years, once the completion was finished the students graduated and went on with their various careers and the experiential knowledge was totally lost from the project. By having overlapping capstone projects working on the same goals, the experience and working knowledge is maintained and successfully passed on to other team members.

The third change made was to have the students create a Robosub Club to encourage younger students to get involved in the project. The club met weekly followed by a pool test where club members were encouraged to suggest ideas for modifications and solutions to current problems. It was hoped that some of these young club members would become excited about the project and select to work on it for their capstone course. The current timeline is shown in Figure 6. 


\section{Lessons Learned}

The outcomes learned can be categorized into two main focus points. The first of the lessons learned are related to the administration and organization of large capstone teams made up of approximately 10 engineering students across three departments. With these large teams it is often a challenge to coordinate advisor time with team members' availability. Also, variations in grading metrics and deliverables across disciplines created conflicts in team dynamics. The different engineering disciplines were focusing on their own discipline deliverables at the expense of total project goals. The second set of lessons learned focus on maintaining the expertise of the team members continually year after year, while attempting to progress further in the competition.

\subsection{Recommendation 1: Synchronizing Capstone Classes across the College}

Before the start of these capstone projects the mechanical and the electrical engineering departments synchronized their capstone courses. They were offered at the same time on the same day. This allowed for students to easily transfer between capstone projects no matter which department they were housed in. The students remained enrolled in their home department capstone courses, but were required to attend and meet the course requirements of the department where the capstone was administered. The computer science department had yet to conform to this model, and numerous conflicts and issues arose.

\subsection{Recommendation 2: Expanded Scheduled Time}

The capstone class times were expanded to a two-hour block. Both the first course in the capstone sequence and the second follow-up course were scheduled at the same time, in the same room, and with the same instructor. The instructor breaks the time block in half and only requires the first course students to attend the first hour and the second hour is reserved for the second capstone students. This enables the off-hour to be used as group meeting times and guarantees that all team members will not have inherent conflicts. These large capstone teams frequency found it difficult to find a time that all team members and faculty advisor could meet before this framework was implemented.

\subsection{Recommendation 3: Build off of Current Design}

Building upon the mindset of engineering, the students all think that they can design a better system than the previous team. Sometimes this was true, but sometimes it was not. Once the students were forced to keep portions of the previous design, more progress was made on the total system design. It also enhanced their critical thinking. They were asked to access the previous design and make recommendations for modifications that addressed the perceived limitations of the current design.

\subsection{Recommendation 4: Maintain Knowledge Base}

Just as it is in industry, it is imperative that the corporate knowledge is maintained to ensure progress. By running parallel teams that are out of phase, each team was able to use the knowledge gleamed from the previous semesters experience to get up to speed 
and become productive much faster. This allowed the following teams to focus on critical bottle necks that hampered previous teams.

\section{Summary}

The experiences gained on large capstone competition teams are very rewarding for the students involved. By making a few small curricular changes the ease at which these projects can be administered are greatly enhanced.

\section{Acknowledgements}

The author would like to thank Mike Kapus and NAVSEA for their continued support of these senior capstone projects.

Bibliography

1. H. Huang, J. Su, C. Lee, “A Contest-Oriented Project for Learning Intelligent Mobile Robots,” IEEE Transactions on Education, Vol. 56, No. 1, February 2013.

2. M. Paulik, M. Krishan, “An Autonomous Ground Vehicle Competition-Driven Capstone Design Course," Proc. of 1999 ASEE/IEEE Frontiers in Education Conference, San Juan, PR, November 10-13, 1999.

3. C. Sulzbach, "Enhancing Engineering Education? Concrete Canoe Competition," Proc. of 2007 ASEE Annual Conference, Honolulu, HI, June 24-27, 2007.

4. B. J. LaMeres, A. Mian, H. Lloyd, R. Larson, "The Montana Mule: A Case Study in Interdisciplinary Capstone Design,” Proc. of 2011 ASEE Annual Conference, Vancouver, BC, June 26-29, 2011.

5. L. Guerra, G. A. Murphy, L. D. May, “Applying Systems Engineering to the Lunabotics Mining Competition Capstone Design Challenge," Proc. of 2013 ASEE Annual Conference, Atlanta, GA, June 23-26, 2013.

6. M. Abdulwahed, M. Benammar, M. O. Hasna, S. Ghani, "Utilizing International Design Competitions for Enhancing $21^{\text {st }}$ Century Engineering Skills," Proc. of 2014 IEEE Frontiers in Education Conference, Madrid, Spain, October 22-25, 2014.

7. J. T. Emison, K. Yoshino, S. E. Straits, H. D. Voss, "Satellite Design for Undergraduate Senior Capstone," Proc. of 2014 ASEE Annual Conference, Indianapolis, IN, June 15-18, 2014.

8. R. E. Larson, D. A. Miller, "A Case Study in Capstone Organization for Continuous Design/Build Projects," Proc. of 2012 ASEE Annual Conference, San Antonio, TX, June 10-13, 2012.

9. M. J. Paulik, M. Krishnan, “A Competition-Motivated Capstone Design Course: The Results of a Fifteen-Year Evolution,” IEEE Transactions on Education, Vol. 44. No. 1, February 2001.

10. 2015 Detailed Competition Map, available online at: http://www.auvsifoundation.org/competitions/competition-central/robosub/robosub-team-central

11. 2015 General Course Layout, available online at: http://www.auvsifoundation.org/competitions/competitioncentral/robosub/robosub-team-central

12. 2015 RoboSub Competition Offical Rules and Mission, available online at: http://www.auvsifoundation.org/competitions/competition-central/robosub/robosub-team-central 